\title{
FUNDAMENTO HISTÓRICO-JURÍDICO DEL RECARGO DE PRESTACIONES: DE SU ORIGEN A LA PROHIBICIÓN DE ASEGURAMIENTO
}

\author{
Dr. Guillermo García González \\ Profesor Titular de Derecho del Trabajo y de la Seguridad Social \\ Universidad Internacional de La Rioja
}

\begin{abstract}
El presente artículo analiza desde una perspectiva histórico-jurídica los fundamentos del recargo de prestaciones, figura de larga tradición en nuestro ordenamiento y que constituye una de las instituciones más controvertidas de nuestro sistema jurídicolaboral. El estudio examina el tránsito que lleva al recargo de prestaciones de su posibilidad de aseguramiento inicial a su prohibición en la Ley de Accidentes del Trabajo de 1922; y ello, con el fin de comprender qué motivos llevaron al legislador a este cambio de criterio que tiene una indudable trascendencia, no solo desde un punto de vista práctico, sino también desde la dogmática jurídica por cuanto incide sustancialmente en la naturaleza de la institución objeto de análisis.

This article analyses the basis of benefit surcharges from a historical-legal perspective, which is a longstanding concept in our legal system and one of the most controversial institutions of our labour-legal system. The study goes over the evolution of benefit surcharges from the initial insuring possibility to its prohibition with the 1992 Law on Accidents at Work. The aim of this essay is to understand the reasons behind the legislator's change of criteria, an event with an undeniable significance, both from a practical point of view and from the legal dogma perspective, as far as it substantially affects the nature of the analyzed institution.
\end{abstract}

Title: Historical-legal basis of benefit surcharges: from its origin to the insuring prohibition

Palabras clave: accidentes de trabajo, aseguramiento, prevención de riesgos laborales, recargo de prestaciones.

Keywords: industrial accidents, insuring, occupational risk prevention, benefit surcharges.

IUSLabor 1/2020, ISSN 1699-2938, p. 157-180

DOI. 10.31009/IUSLabor.2020.i01.06 
Fecha envío: 7.2.2020 | Fecha aceptación: 25.2.2020

\section{Sumario}

1. A modo de introducción: el recargo de prestaciones en la Ley de Accidentes del Trabajo de 1900 como concesión parcial a la teoría de la culpa

2. La configuración primigenia del recargo de prestaciones: la indemnización adicional por falta de medidas de seguridad

3. La aplicación de la indemnización adicional por falta de medidas de seguridad por la primera jurisprudencia

4. El lícito aseguramiento de la indemnización adicional por falta de medidas de seguridad en la primera legislación social

5. Tránsito y culminación de la prohibición de aseguramiento del recargo de prestaciones

6. Breve reflexión final 


\section{A modo de introducción: el recargo de prestaciones en la Ley de Accidentes del Trabajo de 1900 como concesión parcial a la teoría de la culpa}

La Ley de Accidentes del Trabajo de 30 de enero de $1900^{1}$ (LAT, en adelante) supone en la historia de la legislación social en España el punto de inflexión entre lo que se ha denominado fase de emergencia de la legislación de trabajo y su fase de crecimiento y consolidación $^{2}$. La promulgación de la LAT trajo consigo la quiebra insuperable de los principios liberales que propugnaban el abstencionismo normativo estatal en la regulación de las relaciones laborales, comenzando a abrirse paso la legislación protectora del obrero frente a los "exagerados prejuicios individualistas"

Múltiples aportaciones pueden destacarse de la LAT. Sobre todas ellas, especial relevancia presenta la instauración en nuestro ordenamiento jurídico de la doctrina del riesgo objetivo, según la cual el que pone en marcha fábricas o medios mecánicos potencialmente peligrosos debe hacer frente a los siniestros producidos por los mismos aunque no exista culpa o negligencia ${ }^{4}$. Se conforman de este modo las consecuencias económicas del accidente de trabajo como uno de los gastos de la producción que ha de asumir el patrono. Esta teoría suponía que la responsabilidad derivada del accidente de trabajo abandonaba el terreno del derecho privado y se internaba en el ámbito del derecho público 5 .

Hasta 1900, la injusticia social que representaba dejar desvalido al hombre inutilizado en el trabajo había sido paliada por la caridad del patrono o por la beneficencia privada o pública. La actuación de los poderes públicos tenía carácter residual y su papel era

\footnotetext{
${ }^{1}$ Gaceta, 31 de enero de 1900.

2 Martín VAlverde, A., "La formación del derecho del trabajo en España", en AAVV, La legislación social en la historia de España de la Revolución liberal a 1936, Congreso de los Diputados, Madrid, 1987, p. LIV. En el mismo sentido, SuÁREZ GonZÁLEZ, F., Derecho del Trabajo, $4^{\mathrm{a}}$ ed., UNED, Madrid, 1986, p. 102. Otro sector doctrinal enmarca a esta norma dentro de lo que se ha calificado como etapa filantrópica de la legislación laboral y que abarca el periodo comprendido entre 1873 y 1917. Cfr. Montoya Melgar, A., "La seguridad social española: notas para una aproximación histórica", Revista de Trabajo, $\mathrm{n}^{\circ} 54$ (1976), p. 11.

3 Álvarez-Buylla y GonzÁlez-Alegre, A., El obrero y las leyes, Imprenta de la Revista de Legislación, Madrid, 1905, p. 340. Cfr. MARTín VALVERDE, A., "La formación del derecho del trabajo en España", cit., p. LXIV.

${ }^{4}$ La consagración del principio de riesgo profesional confirió a la LAT "un carácter especialmente avanzado en el contexto limitado del reformismo social español de finales de siglo". MONTERO GARCíA, F., "La polémica sobre el intervencionismo y la primera legislación obrera en España: 1890- 1900 (parte II) El debate político parlamentario", Revista de Trabajo nº 61 y 62 (1981), p. 38.

5 JAY, R., La protección legal de los trabajadores, Revista de Legislación y Jurisprudencia, Madrid, 1905 , p. 75.
} 
supletorio respecto de la caridad privada ${ }^{6}$. Se entendía que la idea de desigualdad era esencial en toda sociedad humana, y que del juego de aquella con el principio de responsabilidad surgía espontáneamente la caridad como virtud privada y la beneficencia entendida como servicio administrativo ${ }^{7}$. Excepcionalmente, en alguna ocasión, el trabajador accidentado o sus causahabientes podían resarcirse de los daños causados, no sin un considerable esfuerzo, mediante una demanda de indemnización basada en la responsabilidad civil que pudiera corresponder al patrono por delito, culpa o negligencia ${ }^{8}$.

Toda esta situación dará un vuelco con la promulgación de la LAT que, configurando normativamente la figura del accidente de trabajo, reconoce el derecho que tiene el obrero a ser indemnizado por su patrono por las lesiones que sufra con ocasión o por consecuencia del trabajo que realiza, tomando como base teórica la doctrina del riesgo profesional.

Junto con la doctrina del riesgo objetivo, la LAT y el Real Decreto de 28 de julio de $1900^{9}$ dictado para su aplicación (RDLAT, en adelante) introducen una serie de nociones jurídicas de gran acierto técnico y que han venido siendo mantenidas por la legislación posterior hasta nuestros días. Entre otros, quedan delimitados los conceptos de accidente de trabajo, patrono y operario, y se esbozan institutos tan esenciales como el salario, el contrato de trabajo, el concepto de derecho laboral irrenunciable y el de justicia gratuita ${ }^{10}$. Además de todos ellos, la LAT conforma por primera vez en nuestro ordenamiento el actualmente denominado recargo de prestaciones ${ }^{11}$, institución singular $\mathrm{y}$ de fuerte arraigo en nuestra tradición jurídica que, con pequeños cambios, ha pervivido hasta nuestros días con inusual resistencia ${ }^{12}$.

\footnotetext{
${ }^{6}$ ARIAS MiRANDA, J., Reseña histórica de la beneficencia española, Imprenta del Colegio de Sordomudos y de ciegos, Madrid, 1862, p. 149.

${ }^{7}$ HernÁNDez Iglesias, F., La Beneficencia en España, Manuel Minuesa, Madrid, 1876, tomo I, p. 131.

${ }^{8}$ Gallart Folch, A., Derecho español del trabajo, Editorial Labor, Barcelona,1936, p. 278.

${ }^{9}$ Gaceta, 4 de agosto de 1900.

10 Cfr. De La Villa GiL, L.E., "La influencia de la Ley de Accidentes de Trabajo de 1900 en la construcción del ordenamiento laboral español", en AAVV, Cien Años de la Seguridad Social, Fraternidad Muprespa y UNED, Madrid, 2000, pp. 3-35.

${ }^{11}$ La denominación actual, recargo de prestaciones, fue empleada por primera vez en el artículo 147 del Decreto 907/1966, de 21 de abril, por el que se aprueba el texto articulado primero de la Ley 193/1963, de 28 de diciembre, sobre Bases de la Seguridad Social.

12 Sempere NaVArRo, A. Y Martín JimÉnez, R., "El recargo de prestaciones: puntos críticos", Revista del Ministerio de Trabajo y Asuntos Sociales, $\mathrm{n}^{\circ} 53$ (2004), p. 395. En el mismo sentido, Monereo PÉREZ, J.L., El recargo de prestaciones por incumplimiento de medidas de seguridad e higiene en el trabajo. La modernización de una institución tradicional, Cívitas, Madrid, 1992, p. 15.
} 
La LAT establece en su artículo $5.5^{\circ}$ que, en el caso de que el patrono no hubiera respetado las medidas de seguridad previstas por la ley, las prestaciones económicas a favor del operario accidentado gozarán de un recargo, aumentándose en una mitad más su cuantía. Esta disposición fue desarrollada posteriormente por el artículo 64 RDLAT y reproducida por los artículos 50 y 51 del RD de 26 de marzo de 1902, por el que se aprueba el Reglamento de aplicación de la LAT al ramo de guerra, y por el artículo 35 del Real Decreto de 2 de julio de 1902, de aplicación de la misma norma al ramo de la marina ${ }^{13}$.

El recargo tiene en la LAT la consideración de una indemnización adicional que se suma a la general por responsabilidad objetiva del empresario cuando concurre culpa por infracción de medidas de seguridad, suponiendo una concesión parcial del legislador a la teoría de la culpa en la que se había basado con anterioridad el derecho del obrero a ser indemnizado ${ }^{14}$. En este sentido, ha de tenerse presente que el artículo 16 LAT configura el principio de inmunidad, conforme al cual quien percibe las indemnizaciones previstas legalmente por el sistema de responsabilidad objetiva por accidentes de trabajo no puede ejercitar la acción civil por culpa para la reparación del daño. Esta limitación podía defenderse con base en el carácter objetivo de la responsabilidad, pero era menos justificable cuando en el siniestro concurriera culpa del empresario por haber omitido las medidas de seguridad legalmente determinadas; para estos casos, se introduce el art 5.5 ${ }^{\circ}$ LAT. Así, junto con la doctrina del riesgo objetivo según la cual todos los trabajadores accidentados tienen derecho a una prestación tasada legalmente, la LAT introduce la indemnización adicional que se generará a favor de aquellos trabajadores en cuyos accidentes concurran incumplimientos empresariales en materia preventiva, no como fórmula de reparación íntegra del daño, sino como mejora de la protección al obrero cuando mediara culpa empresarial ${ }^{15}$.

\footnotetext{
13 Parada ToRralba, M.I., "El recargo en las prestaciones económicas de la Seguridad Social por accidente de trabajo y enfermedad profesional por falta de medidas de seguridad e higiene. Concepto y análisis jurisprudencial", Revista de Trabajo y Seguridad Social CEF, no 201 (1999), p. 101. En referencia al Real Decreto de 26 de marzo de 1902 resulta interesante, en cuanto novedosa en nuestro ordenamiento jurídico, la responsabilidad directa que impone la norma en su artículo 50 a jefes de servicio o de obras. Establece el precepto que "la falta de observancia de las medidas que hayan de adoptarse y que sea causa de que ocurra algún accidente, hará responsables de éstos a los jefes de obras, servicios etc., y en su virtud, aparte de las demás responsabilidades en que puedan incurrir, se satisfarán a su cargo los jornales e indemnizaciones, etc., que deban abonarse según las disposiciones de la ley".

14 Gallart Folch, A., Derecho español del trabajo, cit., p. 298. En el mismo sentido, vid. Del Peso Y Calvo, C., Manual de Accidentes del Trabajo, Victoriano Suárez, Madrid, 1946, p. 435.

15 Desdentado Bonete, A., "Responsabilidad por los accidentes de trabajo: prestaciones de seguridad social, recargo e indemnización civil adicional", en PUMAR BELTRÁN, N. (coord.), La responsabilidad laboral del empresario: siniestralidad laboral, Bomarzo, Albacete, 2006, p. 62.
} 
Desde su origen el recargo de prestaciones ha recorrido un largo camino históricojurídico que, con distintos cambios, lo ha llevado a su plasmación actual en el artículo 164 de Real Decreto Legislativo 8/2015, de 30 de octubre, por el que se aprueba el texto refundido de la Ley General de la Seguridad Social. En este devenir, el recargo ha sufrido variaciones en su alcance y contenido, si bien la mayor parte de ellas pueden ser consideradas como adjetivas. Entre las sustantivas, especial análisis merece la modificación que se suscita en los primeros años de vigencia de la institución en relación con la posibilidad de su aseguramiento. Así, la inicial posibilidad de asegurar el recargo de prestaciones que se deriva de la LAT queda suprimida por la Ley de Accidentes del Trabajo de 1922, comenzando con esta última norma la prohibición de seguro que afecta al recargo y que ha llegado hasta nuestros días como uno de los aspectos más conflictivos y discutidos de la institución. A analizar el tránsito históricojurídico que lleva al recargo de prestaciones de su posibilidad de aseguramiento a su prohibición se dedica el presente artículo; y ello, con el fin de poder comprender qué motivos llevaron al legislador a este cambio de criterio que tiene una indudable trascendencia, no solo desde un punto de vista práctico, sino también desde la dogmática jurídica por cuanto incide sustancialmente en la naturaleza de la institución objeto de análisis.

\section{La configuración primigenia del recargo de prestaciones: la indemnización adicional por falta de medidas de seguridad}

Como anteriormente se ha anunciado, el artículo 5.5 $5^{\circ}$ LAT configura por primera vez en nuestro ordenamiento jurídico el recargo de prestaciones por ausencia de medidas de seguridad, figura que hundiendo sus "raices en la propia Ley de Accidentes de Trabajo de 1900 (...) ha estado presente en las sucesivas normas sobre riesgos profesionales y seguridad social" ". Las principales características de la indemnización adicional por falta de medidas de seguridad que introduce la LAT se pueden sintetizar en las cinco notas que siguen:

- Carácter complementario del principio de responsabilidad objetiva. Constituye un complemento de la responsabilidad objetiva por accidentes de trabajo que procederá en aquellos casos en los que concurra culpa del patrono al no haber respetado las medidas de seguridad previstas normativamente. Al acoger la LAT la reparación de los daños derivados de accidentes de trabajo como importes tasados objetivamente, se introduce el recargo como un factor que pueda modular la indemnización que percibe el trabajador en aquellos casos en los que concurra culpa preventiva del empleador. En ningún caso se prevé que la utilización de las medidas preventivas

16 GARcía Murcia, J., Responsabilidades y Sanciones en materia de Seguridad y Salud en el Trabajo, $2^{\mathrm{a}}$ ed., Aranzadi, Elcano, 2000, p.154. 
reduzca la responsabilidad objetiva, pues el empleo de tales medidas se conforma normativamente como una obligación empresarial. Fue este uno de los puntos más discutidos desde el mundo patronal. Se entendía que si bien era lógico que se incrementara la indemnización del accidentado o de sus causahabientes en el caso de que concurriera ausencia de medidas preventivas, era también necesario que se establecieran como contrapartida criterios eximentes "a favor del capitalista que emplee los aparatos de precaución. El gasto que se le exige, admite alguna recompensa" ${ }^{17}$.

- Aplicación restrictiva frente a incumplimientos preventivos tasados. El artículo 5.5 LAT limita las indemnizaciones adicionales a aquellos casos en los que los accidentes de trabajo se hubieran producido en un establecimiento u obra cuyas máquinas o artefactos carecieran de los aparatos de precaución preventivos previstos normativamente, y que se concretan a estos efectos en la Real Orden de 2 de agosto de 1900 sobre mecanismos preventivos ${ }^{18}$. Sin perjuicio de ello, el desarrollo reglamentario de la LAT extiende la indemnización adicional a otros supuestos, conteniendo el artículo 64 RDLAT una formulación genérica: "la falta de medidas en el grado e importancia que determina este reglamento, y el incumplimiento de las disposiciones de la ley de 30 de enero de 1900, será motivo suficiente para que se aumente en una mitad las indemnizaciones que correspondan a los obreros". De este modo, el desarrollo reglamentario amplía el ámbito de aplicación del recargo de prestaciones más allá del estricto catálogo de mecanismos preventivos previsto en la Real Orden de 2 de agosto de 1900. En este sentido, el artículo 59 RDLAT enumera situaciones en las que se entiende que existe falta de previsión: cuando se empleen máquinas y aparatos en mal estado, cuando se ejecute una obra o trabajo con medios insuficientes de personal o de material, o cuando se utiliza personal inepto en obras peligrosas sin la debida dirección, circunstancia esta muy frecuente en la fecha de promulgación de la norma ${ }^{19}$. Se aprecia que los casos de falta de prevención

${ }^{17}$ Raventos, S., Ley Sobre Accidentes de Trabajo. Su articulado y comentarios al mismo, [s.n.], Madrid, 1900, p. 7

18 Gaceta, 4 de agosto de 1900. Esta norma se promulga en cumplimiento de lo dispuesto en los arts. 7 LAT y 65 y 67 RDLAT como complemento a las medidas reparadoras contenidas en los referidos textos normativos. El catálogo de mecanismos preventivos de accidentes de 1900 ha sido considerado por la doctrina como la primera norma jurídica netamente preventiva. FERNÁNDEZ MARCOS, L., Derecho de seguridad e higiene en el trabajo, EDIFAP, Madrid, 1995, p. 24. El catálogo era esperado en la época con gran interés, considerándolo como un instrumento necesario para la previsión de los accidentes de trabajo. Días antes de su promulgación, se calificaba al catálogo como "notabilísimo" y se alababa su moderna confección de acuerdo con los últimos avances existentes en Europa sobre la materia. PUYOL Y ALONSO, J., Ley de 30 de enero de 1900 acerca de los accidentes del trabajo y reglamento para su aplicación de 28 de julio de 1900 anotados y concordados, Madrid, Librería de Fernando Fé, 1900, p. 14. ${ }^{19}$ Ibidem, p. 40. 
enumerados reglamentariamente son muy amplios en su enunciación, alcanzando a múltiples supuestos que en virtud del artículo 64 RDLAT darán lugar también al incremento indemnizatorio previsto en el artículo $5.5^{\circ} \mathrm{LAT}^{20}$.

Con todo, y como se analizará en el siguiente apartado, la amplitud de la fórmula reglamentaria se verá de facto desdibujada por la aplicación e interpretación restrictiva que las primeras resoluciones judiciales desarrollan en relación con la institución; interpretación restrictiva que regirá durante décadas y quedará reafirmada por el Tribunal Supremo. Así, se entendía que "al constituir el objeto de los preceptos reglamentarios la más fácil aplicación de las leyes, sin extender ni restringir las sanciones que establezcan, hay que deducir que, aun cuando por sus términos literales pudiera suponerse aplicable el artículo 64 a los casos de total inobservancia de los preceptos generales de la ley, en modo alguno cabe aplicar dicho texto a otras omisiones del patrono" distintas de las recogidas en el artículo $5.5^{\circ} \mathrm{LAT}^{21}$. Por tanto, en la práctica, la virtualidad de la indemnización adicional se anudará casi exclusivamente a aquellos supuestos en los que expresamente se pueda probar la ausencia de algún mecanismo de los contenidos en la Real Orden de 2 de agosto de 1900 sobre mecanismos preventivos.

- Porcentaje de incremento fijo frente a cualquier tipo de prestación. El incremento de las indemnizaciones es fijo ${ }^{22}$, aumentándose las prestaciones en una mitad más de su cuantía, y se genera frente a cualquier tipo de prestaciones y no solo en aquellas que deriven de fallecimiento. Es este el sentido que ha sido mantenido por la doctrina más autorizada y que debe ser acogido ${ }^{23}$. Este criterio se deduce del propio literal del precepto en relación con la reproducción que del mismo realiza el artículo 64

20 En este sentido, la expresión "medios insuficientes de personal o de material" contaba con extraordinaria amplitud para que por vía interpretativa se incluyeran en este supuesto de falta de previsión a muchos de los accidentes de trabajo acaecidos.

21 STS, 28 de mayo de 1918. Cfr. Rodríguez Martín, A. Y Alarcón HorCAS, S., Accidentes del Trabajo (teoría y práctica de la responsabilidad), Editorial Reus, Madrid, 1923, pp. 347 y 348.

22 El carácter variable del recargo, entre el 30\% y el 50\%, no se introduce hasta el Decreto 907/1966, de 21 de abril, aprobando el texto articulado primero de la Ley 193/1963, de 28 de diciembre, sobre Bases de la Seguridad Social ( artículo 147).

23 Entre la doctrina de la época apoyan esta teoría DEL NIDO Y TORRES, M., Ley de Accidentes del Trabajo comentada y concordada, Escuelas profesionales de artes y oficios, Sevilla, 1911, p. 29. También la doctrina contemporánea avala esta interpretación. Vid. PURCALLA BonILLA, M.A., El recargo de prestaciones por incumplimiento de normas de seguridad y salud laboral. Análisis crítico de su configuración jurídico- positiva, Comares, Granada, 2000, p. 19. En contra de esta opinión se muestra la interpretación aislada de FERNÁNDEZ MARCOS, L., Ensayos sobre temas actuales de seguridad e higiene en el trabajo, UNED, Madrid, 1992, p. 8, que entiende que el recargo únicamente procedía en el caso de prestaciones derivadas de fallecimiento. 
RDLAT y el artículo 51 del Real Decreto de 26 de marzo de 1902, por el que se aplica la LAT al ramo de la guerra. El Tribunal Supremo consagró finalmente esta interpretación en sus resoluciones de 28 de octubre de 1911 y de 21 de octubre de 1915.

- Naturaleza jurídica esencialmente indemnizatoria. Pese a la continuidad de su definición en el tiempo, la naturaleza jurídica del recargo por ausencia de medidas de seguridad ha sido uno de los temas más debatidos por el iuslaboralismo, siendo considerada por un sector doctrinal como una sanción, por otro como una indemnización, y por un tercero como una figura de naturaleza híbrida, a modo de la indemnización punitiva de tradición anglosajona; un debate este eterno y laberíntico que no ha llegado tras décadas de análisis y miles de hojas escritas a ninguna solución que se pueda considerar satisfactoria o que genere consenso doctrinal. Las dudas sobre la naturaleza jurídica del recargo de prestaciones han sido objeto de infinitos análisis y abordadas desde múltiples perspectivas teóricas. Tras más de un siglo de producción científica, tesis doctorales e interminables debates dogmáticos, los constructos sobre la naturaleza jurídica del recargo siguen pivotando sobre las mismas variables ${ }^{24}$. En la primigenia configuración de la LAT, el hecho de que se instituyera esta figura con fines reparadores del accidentado o indemnizatorios, la posibilidad de ser objeto de transacción y la circunstancia de que se permitiera asegurar el recargo, llevan a incardinar esta medida legal dentro del sistema resarcitorio civil ${ }^{25}$. Con todo, el recargo en las indemnizaciones suponía también la imposición al infractor de una especie de sanción económica con evidentes fines preventivos $^{26}$. Su propia ubicación en la LAT, en su apartado $5.5^{\circ}$, inmediatamente antes de los preceptos dedicados a la prevención de riesgos laborales apoyan su finalidad preventiva ${ }^{27}$. Idéntica conclusión se obtiene si se atiende a los artículos 64

\footnotetext{
${ }^{24}$ Ilustrativa resulta a estos efectos la lectura de Montoya Melgar, A., "Sanción e indemnización: el recargo de las indemnizaciones por accidentes de trabajo", Anuario de Derecho Civil, no 3 (1967), pp. 515-536. Medio siglo después, las premisas recogidas por el autor siguen en buena medida vigentes y sirviendo de base para profusos debates doctrinales.

${ }^{25}$ FeRnÁNDEZ DoCAMPO, M.B., Seguridad y salud laboral en las obras de construcción: obligaciones y responsabilidades, Aranzadi, Cizur Menor, 2003, p. 244. Un completo estudio sobre las posiciones doctrinales en relación con la naturaleza del recargo en PURCALla Bonilla, M.A., El recargo de prestaciones por incumplimiento de normas de seguridad y salud laboral. Análisis crítico de su configuración jurídico- positiva, cit., pp. 37 a 80.

26 García Murcia, J., Responsabilidades y Sanciones en materia de Seguridad y Salud en el Trabajo, cit., p. 29. En el mismo sentido, Hernáinz MÁrquez, M., Accidentes del Trabajo y Enfermedades Profesionales, Revista de Derecho Privado, Madrid, 1945, p. 259, y Fernández MARCos, L., La seguridad e higiene del trabajo como obligación contractual y como deber público, Servicio de Publicaciones del Ministerio de Trabajo, Madrid, 1975, p. 31.

${ }^{27}$ MARTÍNEZ LUCAS, J.A., "Los orígenes del recargo de prestaciones económicas en caso de accidente
} 
y 67 RDLAT que contemplan la figura del recargo con fin esencialmente indemnizatorio del operario accidentado, pero dirigido "preferentemente a la prevención de accidentes de trabajo" ${ }^{28}$.

- Inserta en un embrionario sistema de responsabilidades. El régimen de responsabilidades diseñado por la LAT y por el RDLAT es confuso y poco elaborado $^{29}$. El principio de inmunidad recogido en el artículo 16 LAT que ha sido expuesto anteriormente, parece de difícil cohabitación con los preceptos reglamentarios que determinan que la indemnización adicional por falta de medidas de seguridad resulta compatible con cualquier tipo de responsabilidad penal, civil o administrativa que se derive de los accidentes de trabajo (artículos 64 y 67 RDLAT).

\section{La aplicación de la indemnización adicional por falta de medidas de seguridad por la primera jurisprudencia}

La LAT es la primera norma sustantiva de nuestro ordenamiento jurídico que introduce un procedimiento especial para los litigios del trabajo ${ }^{30}$. Su artículo 14 conforma una regulación provisional, estableciendo que mientras se dicten las disposiciones relativas a los tribunales o jurados especiales el conocimiento de los conflictos que surjan de la aplicación de la LAT se atribuirá a los jueces de primera instancia, con arreglo a los procedimientos establecidos para los juicios verbales y con los recursos que se determinan en la Ley de Enjuiciamiento Civil $^{31}$. Se dotaba de este modo al juzgado de primera instancia de competencia para conocer los litigios derivados de los accidentes de trabajo y se adoptaban con el fin de primar la celeridad los trámites del juicio

de trabajo y enfermedad profesional", en AAVV, VII Congreso Nacional de Derecho del Trabajo y de la Seguridad Social (ejemplar multicopiado), AEDTSS, Valladolid, 1996, p. 2. Cfr. PURCALLA BonILLA, M.A., El recargo de prestaciones por incumplimiento de normas de seguridad y salud laboral. Análisis crítico de su configuración jurídico- positiva, cit., p. 8, y MONEREO PÉREZ, J.L. y SÁNCHEZ PÉREZ, J., "El recargo de prestaciones y la nueva doctrina jurisprudencial", Trabajo y Derecho, $\mathrm{n}^{\circ} 12$ (2015), pp. 89 y ss.

28 García Murcia, J., Responsabilidades y Sanciones en materia de Seguridad y Salud en el Trabajo, cit., p. 161.

${ }^{29}$ GonzÁlez Rebollar, H., Ley de accidentes del trabajo. Estudio crítico a la española de 30 de enero de 1900, Imprenta de Calón, Salamanca, 1903, p. 309.

30 De Hinojosa FerRer, J., El enjuiciamiento en el derecho del trabajo, Editorial Revista de Derecho Privado, Madrid, 1933, p. 20. En idénticos términos se pronuncia PÉREZ SERRANO, J., La organización y el funcionamiento de los Tribunales de Trabajo en la Legislación comparada y su posible aplicación a España, Sobrinos de la Sucesora de M. Minuesa de los Ríos, Madrid, 1936, p. 190.

${ }^{31}$ El procedimiento de los juicios verbales ante los jueces de primera instancia quedaba regulado en los arts. 715 y ss. de la Ley de Enjuiciamiento Civil. 
verbal $^{32}$. La rapidez en resolver las contiendas atinentes a las clases jornaleras y desvalidas se constituía así como uno de los objetivos principales de la LAT $^{33}$. Por ello, se intentó implementar un procedimiento expedito y poco costoso sin necesidad de formulismos o rituales en la demanda ni asistencia de abogado o procurador obligatoria $^{34}$.

Pese a que se prevé un procedimiento rápido y sencillo, el legislador no quiso que ello fuera en detrimento de las garantías de los justiciables, por lo que se aplica un completo sistema de recursos, como "lo exigía la índole de la nueva legislación" "35. Frente a la sentencia dictada por el juzgado de primera instancia cabía interponer recurso de apelación en la audiencia territorial competente de acuerdo con los artículos 702 y ss. de la Ley de Enjuiciamiento Civil ${ }^{36}$. Contra esta última resolución cabía si se reúnen los requisitos procesales oportunos recurso de casación conforme a los artículos 1689 y ss. del mismo cuerpo legal 37 .

Jueces y tribunales acogieron rápidamente la indemnización adicional por falta de medidas de seguridad y pronto son dictadas sentencias que comienzan a perfilar el alcance y contenido que esta novedosa institución tendrá en la práctica ${ }^{38}$. Un análisis de las primeras sentencias dictadas sobre la materia lleva a concluir que como norma general se aplica el artículo 5.5 $5^{\circ}$ LAT, si bien con un alcance muy limitado y desconociendo la amplitud con la que el legislador dota a la institución ex artículos 59 y

32 Ossorio Y Gallardo, A., Accidentes del Trabajo, Ricardo Rojas, Madrid,1902, p. 43.

33 Zorrilla RuIZ, M.M., Derecho del Trabajo y proceso de cambio social, Publicaciones de la Universidad de Deusto, Bilbao, 1977, p. 21.

34 OYUelos, R., Accidentes del trabajo. Estudio de la Ley, Reglamento, disposiciones complementarias y Jurisprudencia, Legislación Española, Madrid, 1902, cit., p. 200.

35 De Hinojosa Ferrer, J., El enjuiciamiento en el derecho del trabajo, cit., p. 21.

36 Este extremo quedó sentado rápidamente por la STS 6 de octubre de 1902, que casó y anuló un pronunciamiento de la Audiencia de Sevilla que negaba la posibilidad de recurrir en apelación en los juicios sobre accidentes de trabajo. BUYLla, A., "Prólogo", GonZÁlez REBOllar, H., Ley de accidentes del trabajo. Estudio crítico a la española de 30 de enero de 1900, cit., p. XI.

37 SÁNCHEZ De OCAÑA, R., Ley de Enjuiciamiento Civil anotada con la Jurisprudencia, concordada con el Código de Comercio antiguo y con el vigente, y seguida de todas las disposiciones complementarias, $3^{\mathrm{a}}$ ed., Centro Editorial de Góngora, Madrid, 1891, p. 471.

38 Por todas, Sentencias de 23 de octubre y 16 de diciembre de 1901, del Juzgado de primera instancia de Fregenal de la Sierra y de la Audiencia de Cáceres, respectivamente. Instituto de Reformas Sociales, Jurisprudencia de los Tribunales en materia de Accidentes del Trabajo, Suc. de M. Minuesa de los Ríos, Madrid, 1909, pp. 213 y ss. A pesar de que, como ha señalado la doctrina, la figura del recargo contó en sus primeros años de vigencia con "innúmeras reticencias jurisprudenciales que la postergaban". PURCALla Bonilla, M.A., El recargo de prestaciones por incumplimiento de normas de seguridad y salud laboral. Análisis crítico de su configuración jurídico- positiva, cit., p. 20. 


\section{RDLAT.}

Las primeras resoluciones judiciales acogen una línea interpretativa estricta del literal del artículo 5.5 $5^{\circ}$ LAT, omitiendo su desarrollo reglamentario, conforme a la cual solo cabe el recargo de prestaciones si en el accidente se prueba la ausencia de un mecanismo de protección concretamente referido en el catálogo de la Real Orden de 2 de agosto de 1900. Se desconoce por tanto en la práctica judicial la conformación reglamentaria de la indemnización adicional que ampara la imposición del recargo basado en la falta de medidas preventivas previstas normativamente, y entre las que se encuentran la ejecución de una obra o trabajo con medios insuficientes de personal o de material, o el empleo de personal inepto en obras peligrosas sin la debida dirección (artículos 59 y 64 RDLAT)

Además, para que proceda la indemnización por ausencia de aparatos de precaución es necesario que estos aparatos "estén precisa y claramente determinados en la obligatoriedad de su uso por los Reglamentos pertinentes" "39. Así, la Real Orden de 2 de agosto de 1900 se aplica con carácter restrictivo, analizando cada caso concreto y poniendo en relación la existencia de aparatos de seguridad obligatorios en la industria con el accidente acaecido ${ }^{40}$.

Resume perfectamente esta línea interpretativa restrictiva la STS 26 de junio de 1907, que resuelve la pretensión del obrero dirigida a que se le incremente la prestación en su mitad por ausencia de medidas de seguridad frente a un accidente en una fábrica de productos químicos, donde al subir encima de un aparato denominado "de sacrificación" se produce una lesión en el dedo pulgar del pie izquierdo, el cual le fue amputado. En el proceso se emiten tres informes periciales por ingenieros, entendiendo que el referido aparato tiene una función esencialmente química " $y$ no está compuesta de órganos de indole mecánica que exijan las referidas prevenciones". Pese a que se prueba que el obrero se lesionó al realizar el mantenimiento de dicha máquina, la resolución estima que la misma no es de las que necesita especial protección según la Real Orden de 2 de agosto de 1900, "aun cuando el patrono, por precaución, no obligatoria, ni absolutamente necesaria, haya instalado posteriormente alguna" ${ }^{41}$.

Esta tendencia jurisprudencial marcará por mucho tiempo nuestro sistema jurídico, considerándose que solo ante la ausencia de mecanismos de protección

\footnotetext{
39 Del Peso Y Calvo, C., Manual de Accidentes del Trabajo, cit., p. 431.

40 ZARANDIETA, E., El espiritu de la jurisprudencia en los accidentes de trabajo, Ruiz Hermanos, Madrid, 1928, p. 69.

${ }^{41}$ Gaceta de Madrid, 13 de octubre de 1908.
} 
reglamentariamente especificados procederá la imposición del recargo ${ }^{42}$. Se entendía que ello era lógico y obedecía a criterios de justicia, ya que si el señalamiento de cuáles debían de haber sido los aparatos de precaución quedara a merced del juzgador, se llegaría a resultados injustos y desiguales. Por una parte, por la diferencia de criterios del juzgador, y, por otra, porque "la fijación de cuáles deben ser los aparatos de precaución es labor muy ajena de la formación jurídica y propia de aquellos que por sus estudios (médicos, ingenieros, etc.) poseen conocimientos suficientes para poder determinar con claridad qué es lo que es preciso y cuál cosa no lo es" ${ }^{43}$.

Junto con la limitación interpretativa señalada, que restringía sustancialmente el alcance de la institución, la reclamación de la indemnización adicional por parte del obrero accidentado se encontraba con diferentes obstáculos procesales en la práctica. Entre otros, cabe subrayar los que siguen:

- Principio procesal de congruencia. Para determinar la existencia de la indemnización adicional por falta de medidas de seguridad era necesario que el trabajador accidentado lo demandara expresamente, acreditando concretamente qué tipo de mecanismo preventivo de los catalogados estaba ausente, lo que requería que el empleado accidentado se sirviera de peritos. No se puede obviar que los juicios de accidentes de trabajo venían regidos en sus fundamentos por los principios del proceso civil, en los que siguiéndose "la teoría del pleito, el Juez no practica nada de oficio limitándose a dictar su sentencia por la resultancia de las alegaciones y pruebas aportadas por las partes" ". En consecuencia, con lo expuesto, no solo se exige que se pruebe que los aparatos de precaución ausentes se encuentren entre los determinados reglamentariamente, sino que se hace preciso que se solicite el recargo, invocándose la norma legal que exija el aparato de precaución para que

42 Vid. SSTS 3 de noviembre de 1943, 14 de octubre de 1950 y 29 de abril de 1953, que siguen manteniendo los mismos criterios. Servata distantia, cfr. STS, 28 de febrero de 2019 ( $\mathrm{n}^{\circ}$ rec. 508/2017). Sobre este punto, cfr. TomÁs AlEMANY, P., Legislación Social, Vda. de A. Reus, Alicante, 1912, pp. 298 y ss., y HernáinZ MÁrqueZ, M., Tratado elemental de Derecho del Trabajo, $8^{\mathrm{a}}$ ed., Instituto de Estudios Políticos, Madrid, 1961, pp. 612 y 613.

${ }^{43}$ En estos términos se expresa Del Peso Y Calvo, C., Manual de Accidentes del Trabajo, cit., p. 431.

44 Aumatell Tusquets, F., Estudios de la Ley de 30 de enero y sus disposiciones complementarias, seguido de un sucinto examen comparativo de la legislación extranjera, Librería de Penella y Bosch, Barcelona, 1903, p. 106. En contra de esta opinión, algunos comentaristas de la época sostenían que del espíritu de la LAT y de su reglamento de aplicación se podía extraer el principio de actuación de oficio por parte del juez civil, no siendo este el único caso en que por circunstancias especiales y por ser de alta conveniencia social el juez actué de oficio en asuntos de carácter civil. GONZÁLEZ REBOLLAR, H., Ley de accidentes del trabajo. Estudio crítico a la española de 30 de enero de 1900, cit., p. 397. En el mismo sentido, Oyuelos, R., Accidentes del trabajo. Estudio de la Ley, Reglamento, disposiciones complementarias y Jurisprudencia, cit., p. 205. 
proceda el aumento en la cuantía de la indemnización ${ }^{45}$.

- Alcance y extensión del allanamiento del demandado. El allanamiento del patrono a la pretensión del demandante solo tenía efectos en cuanto al importe de la prestación, pero no determinaba que el patrono reconociera la ausencia de medidas precautorias a los efectos de ulteriores consecuencias o responsabilidades ${ }^{46}$.

- El recargo indemnizatorio por ausencia de medidas de seguridad puede constituir lícito objeto de transacción entre las partes, siendo posible el acuerdo de ambas sobre el importe del mismo y teniendo este pacto medidas liberatorias para el patrono ${ }^{47}$. Se abría por esta vía la posibilidad de que el empleador eludiese el total cumplimiento de la indemnización pactando con el obrero en el momento del accidente una cantidad menor, lo que no era difícil que ocurriera teniendo en cuenta lo perentorio de las necesidades de los obreros.

\section{El lícito aseguramiento de la indemnización adicional por falta de medidas de seguridad en la primera legislación social}

La LAT configura por primera vez en nuestro ordenamiento jurídico un seguro de accidentes de trabajo. En su artículo 12 determina que los patronos "podrán sustituir las obligaciones definidas en los artículos $4 .^{\circ}, 5 .^{\circ}$ y 10 , o cualquiera de ellas por el seguro hecho a su costa en cabeza del obrero de que se trate, de los riesgos a que se refiere cada uno de esos artículos respectivamente o todos ellos, en una Sociedad de seguros debidamente constituida, que sea de las aceptadas para ese efecto por el Ministerio de la Gobernación, pero siempre a condición de que la suma que el obrero reciba no sea inferior a la que correspondiera con arreglo a esta ley".

Aparecen en esta concepción del seguro de accidentes de la LAT las primeras notas de lo que con posterioridad se convertirá en el seguro social obligatorio; es un seguro hecho a costa del patrono, se conforman una serie de prestaciones asegurables determinadas normativamente, y se regulan unas garantías reforzadas del pago de dichas prestaciones.

\footnotetext{
45 Sentencia del Juzgado de primera instancia de Fuenteovejuna de 28 de octubre de 1904. Boletín del Instituto de Reformas Sociales, $\mathrm{n}^{\circ} 15$ (1905), p. 207. Cfr. Sentencia del Juzgado de primera instancia de Salas de los Infantes de 17 de noviembre de 1904. Boletín del Instituto de Reformas Sociales, $\mathrm{n}^{\mathrm{o}} 16$ (1905), p. 291.

46 Sentencia del Juzgado de primera instancia del distrito de la Barceloneta de Barcelona de 29 de diciembre de 1906. Boletín del Instituto de Reformas Sociales, $\mathrm{n}^{\circ} 103$ (1913), p. 91.

47 Vid. Sentencia de la Audiencia de Barcelona de 19 de octubre de 1905. Instituto de Reformas Sociales, Jurisprudencia de los Tribunales en materia de Accidentes del Trabajo, cit., pp. 470 y ss.
} 
La introducción del seguro de accidentes en el marco de las relaciones productivas en los inicios del s. XX se vio favorecida por varios factores. El seguro de accidentes era menos costoso para el Estado que otros seguros sociales, justificándose desde la concepción moral de la época en mayor medida que otros seguros, como por ejemplo el de enfermedad, ligado tradicionalmente en la visión patronal a eventuales fraudes. Además, la existencia de antecedentes legislativos que amparaban la reclamación aunque fuera teórica- por el trabajador accidentado al empresario, facilitaba la admisión del seguro de accidentes ${ }^{48}$.

La LAT configura el seguro de accidentes con carácter de seguro voluntario o facultativo, teniendo como finalidad la cobertura de la responsabilidad patronal por los siniestros laborales establecida en la misma norma. El riesgo que el empresario puede asegurar son todas o parte de las indemnizaciones u obligaciones que tiene el patrono en el caso de que acaezca un siniestro laboral. La amplitud de la fórmula legal "podrán sustituir las obligaciones definidas en los artículos $4 .^{\circ}, 5 .^{\circ}$ y 10 , o cualquiera de ellas" amparaba sin género de dudas la posibilidad de asegurar la indemnización adicional del artículo 5.5 . Sin embargo, las entidades aseguradoras no compartían dicha interpretación, estimando que la indemnización adicional no resultaba asegurable.

El debate quedó zanjado provisionalmente con la resolución del Tribunal Supremo de 23 de noviembre de $1905^{49}$. En esta sentencia, el Tribunal Supremo admite el aseguramiento del recargo de las indemnizaciones recogido en el artículo 5.5 ${ }^{\circ}$ LAT. El supuesto de referencia se ocupa de la muerte de un obrero que trabajaba como operario en la sección de tinte de una fábrica de paños en Alcoy y que fallece por intoxicación. La compañía aseguradora se negaba a asumir el pago derivado de esa responsabilidad por el carácter de pena de la misma, alegando que en los contratos no cabe pacto contrario a la ley o a las buenas costumbres, según los artículos 1255 y 1271 del Código Civil, siendo contrario a las leyes, a la moral y al orden público y buenas costumbres eludir el cumplimiento de una pena, porque la primera condición de la pena es ser personal $^{50}$. La compañía aseguradora mantiene que "siendo el aumento de indemnización impuesto por la Ley (...) la pena o sanción que la propia Ley impone al

\footnotetext{
48 Silvestre RodrígueZ, J. y PONS PONS, J., "El seguro de accidentes del trabajo, 1900-1935. El alcance de las indemnizaciones, la asistencia sanitaria y la prevención", en PONS PONS, J. y SILVESTRE RODRíGUEZ, J. (coord.), Los orígenes del estado de bienestar en España, 1900-1945 los seguros de accidente, vejez, desempleo y enfermedad, Prensas Universitarias de Zaragoza, Zaragoza, 2010, pp. 123 y SS.

49 Instituto de Reformas Sociales, Jurisprudencia de los Tribunales en materia de Accidentes del Trabajo, cit., pp. 22 y ss.

50 García Ormaechea, R. Jurisprudencia del Tribunal Supremo y de la Comisión Superior de Previsión sobre Accidentes de Trabajo: 1902-1934, Sucesores de M. Minuesa de los Ríos, Madrid, 1935, p. 588.
} 
patrono que infringe sus disposiciones no teniendo en fábricas, obras o explotaciones los aparatos de evitación de accidentes a que la propia Ley se refiere, y como el pensamiento de la Ley al establecer tal sanción no es otro que el obligar al uso de tales aparatos de precaución en evitación de accidentes, vendría a ser burlado desde el momento que se entendiera comprendido en el seguro, y por ende a cargo de persona distinta, el cumplimiento de tal sanción" ${ }^{51}$.

La resolución del Tribunal Supremo no acoge el posicionamiento de la compañía aseguradora y determina que, "hallándose facultados los patronos para sustituir las obligaciones que se especifican en los artículos $4^{\circ}, 5^{\circ}$, y $10^{\circ}$ de la Ley de Accidentes del Trabajo, o cualquiera de aquellas, por el contrato de seguro hecho a su costa en cabeza de obrero, es incuestionable que en el celebrado por (...) la Sociedad demandada sustituyó ésta al patrono (...) en las obligaciones que sancionara el mencionado articulo $5^{\circ}$, sin exceptuar ninguna, y, por tanto, se halla obligado a responder al aumento que establece la quinta disposición de aquel, aumento que no reviste carácter de pena personal, como con error supone el recurrente, sino el de una responsabilidad de orden meramente civil, como todas las demás de dicho artículo, por lo que al aplicar el Tribunal sentenciador a la Sociedad aseguradora la sanción de la disposición $5^{a}$ antes citada no ha infringido los artículos del Código civil" ${ }^{52}$.

Quedaba sentada por esta sentencia el lícito aseguramiento de la indemnización adicional por ausencia de mecanismos preventivos.

Con el fin de evitar responsabilidades, gran parte de compañías y sociedades mutuas excluyeron expresamente de sus coberturas del seguro de accidentes dicha indemnización 53 . Además, y como se verá seguidamente, las compañías aseguradoras, lejos de resignarse con la decisión del Tribunal Supremo, promoverán distintas acciones que culminarán con la prohibición legal del aseguramiento del recargo en la Ley de Accidentes del Trabajo de 1922.

51 Instituto de Reformas Sociales, Jurisprudencia de los Tribunales en materia de Accidentes del Trabajo, cit., p. 27.

52 Ibidem, p. 28.

53 Cfr. artículo 9, Estatutos de la Mutua Catalana de Accidentes de Trabajo, Tipografía La Académica, de Serra Hnos. y Rusell, Barcelona, 1905, p. 7; artículo 20, Estatutos de la Mutua para Accidentes del Trabajo del Sindicato Protector del Trabajo Nacional, Tipografía Vda. de D. Casanovas, Barcelona, 1907, p. 19; y artículo 40, Estatutos de la Sociedad Gremial de Cerrajeros y Herreros de Barcelona y Mutua sobre Accidentes del Trabajo, Imprenta de Henrich y C., Barcelona, 1904, p. 18. 


\section{Tránsito y culminación de la prohibición de aseguramiento del recargo de prestaciones}

La aplicación de la LAT trajo consigo fuertes problemas interpretativos $\mathrm{e}$ insatisfacciones tanto de los actores políticos como de los agentes sociales. El movimiento obrero, el patronal y también las compañías aseguradoras rápidamente comenzaron a solicitar que la norma fuera reformada en algunos aspectos. Haciéndose eco de esa inquietud reformista, el pleno del Instituto de Reformas Sociales aprobó el 28 de junio de 1907 el proyecto de reforma de la LAT, elevándolo al Gobierno para su presentación a las Cortes ${ }^{54}$.

Entre los contenidos objeto de reforma, el proyecto introduce la prohibición de aseguramiento de la indemnización adicional en su artículo $6.5^{\circ}$, tratando de corregir el sentido dado por la resolución de 23 de noviembre de 1905 del Tribunal Supremo en relación con este extremo. El precepto quedó redactado de la siguiente forma:

"Las indemnizaciones determinadas por esta ley se aumentarán en una mitad más de su cuantía cuando el accidente se produzca en un establecimiento u obra cuyas máquinas o artefactos carezcan de los aparatos de precaución a que se refiere el artículo 17.

El riesgo de la indemnización especial a que se refiere esta disposición $5^{a}$ no puede ser materia de seguro. Si se probare que alguna entidad aseguradora lo asumía, deberá ser apercibida, y, caso de persistir en pactar dicha condición, se le retirará la autorización oficial que se le hubiere concedido a los efectos de la presente ley".

Pese a que el proyecto de 1907 no cristalizó normativamente, la referencia a la prohibición de aseguramiento de la indemnización que introduce tiene una trascendencia indudable en la historia jurídica del recargo de prestaciones; y ello, por un doble motivo. Por una parte, por ser la primera vez que se introduce en el debate público e institucional la prohibición del aseguramiento del recargo; y, por la otra, porque a partir de este proyecto se irán generando otros que acogerán literalmente la redacción dada por el de 1907 y que, tras múltiples fracasos, quedará consolidada en el ordenamiento jurídico en el artículo $6.5^{\circ}$ de la Ley de Accidentes del Trabajo de 1922 que reproduce literalmente la redacción promovida por el proyecto de 1907.

Las razones aludidas hacen especialmente relevante el análisis de los trabajos previos y de la discusión que se llevó a cabo para la introducción de la prohibición del

54 Boletín del Instituto de Reformas Sociales, n 36 (1907), pp. 981 a 994. El proyecto contó con votos particulares de Joaquín Sánchez de Toca, Pedro J. Moreno Rodríguez y José Maluquer y Salvador. 
aseguramiento del recargo en el seno del Instituto de Reformas Sociales en el marco del proyecto de reforma de la LAT de $1907^{55}$.

De un examen detallado de estos trabajos preparatorios se obtienen distintas conclusiones que, a efectos de mejor comprensión, son expuestas de forma cronológica.

La moción que presentan los vocales de la clase obrera al Instituto de Reformas Sociales, el 23 de abril de 1904, proponiendo modificaciones y adiciones a la LAT, no hace ninguna referencia al aseguramiento del recargo. Pese a que los vocales obreros solicitan numerosas reformas en relación con el artículo 5 LAT, la indemnización adicional contemplada en su apartado $5^{\circ}$ no es objeto de observaciones, lo que hace presumir la conformidad obrera con la redacción original del referido precepto 56 . La admisibilidad del aseguramiento del recargo parece que no ofrece discusión desde la perspectiva obrera, máxime si se atiende a que gran parte de sus solicitudes de modificación iban dirigidas a dotar al sistema protector de las máximas garantías público-privadas para facilitar la efectiva percepción de las indemnizaciones legalmente previstas, lo que colisionaba frontalmente con la exclusión de la indemnización adicional del posible objeto del seguro de accidentes.

El debate sobre el aseguramiento de la indemnización adicional fue introducido por las observaciones que a la reforma de la LAT realiza la Comisión permanente de las

55 El Instituto de Reformas Sociales es creado por Real Decreto de 23 de abril de 1903 (Gaceta, 30 de abril de 1903) en el seno del Ministerio de Gobernación, con el encargo, según reza su primer artículo, de “preparar la legislación del Trabajo en su más amplio sentido, cuidar de su ejecución, organizando para ello los necesarios servicios de inspección y estadística, y favorecer la acción social y gubernativa en beneficio de la mejora o bienestar de las clases obreras". El Instituto será presidido desde su creación por Gumersindo de Azcárate y se configura como el principal impulsor de la futura legislación social, realizando labores de preparación legislativa y teniendo al mismo tiempo libertad de iniciativa normativa, pero sometiendo siempre sus propuestas a la aprobación del Gobierno, que en no pocas ocasiones habría de limitar sus propuestas más "coherentemente reformadoras". PALOMEQUE LOPEZ, M.C., Derecho del trabajo e ideología, $4^{\mathrm{a}}$ ed., Tecnos, Madrid, 1989, p. 66. El Instituto representaba en su composición a todos los sectores implicados en la cuestión social, estando formado por treinta miembros: dieciocho nombrados por el Gobierno y que constituían la representación técnica, seis miembros como representantes patronales y seis miembros más por parte de la representación obrera. El Instituto de Reformas Sociales realiza sus funciones a través del Instituto en corporación, es decir, en pleno, y a partir de los servicios administrativos. Los servicios administrativos se componen de una secretaría general y tres secciones técnico- administrativas, encargadas respectivamente de legislación e información bibliográfica (sección primera), inspección (sección segunda) y estadística (sección tercera). PALACIO MorenA, J.I., La institucionalización de la reforma social en España, Centro de Publicaciones del Ministerio de Trabajo y Seguridad Social, Madrid, 1988, p. 65.

56 Moción proponiendo modificaciones y adiciones a la Ley de Accidentes del Trabajo que presentan al Instituto de Reformas Sociales los vocales elegidos por la clase obrera, Imprenta de la Sucesora de M. Minuesa de los Ríos, Madrid, 1904, pp. 11-14. 
compañías de seguros de accidentes ${ }^{57}$. La sección primera técnico-administrativa del Instituto de Reformas Sociales proporciona, el 10 de abril de 1905, una respuesta detallada a las propuestas de las empresas aseguradoras. Así, y teniendo en cuenta " $l a$ importancia de las entidades que envían al Instituto su parecer, y que representan dichas entidades intereses de gran monta, creados al amparo de la Ley que se trata de reformar, la Sección estima indispensable examinar el trabajo presentado de una manera especial, ya que conviene recoger la mayor suma de opiniones y de experiencias en esta labor preparatoria de reforma de una Ley como la de Accidentes, cuyos resultados positivos nadie pone en duda" $" 58$.

Como principio rector de su propuesta, la asociación de empresas aseguradoras aboga por el establecimiento de un seguro de accidentes de índole privado y mercantil, desechando el seguro de accidentes público y obligatorio por "los grandes y graves inconvenientes que tal institución, de carácter genuinamente socialista, lleva en si ",59. Respecto de la indemnización adicional, la Comisión permanente de compañías de seguros de accidentes entiende que no puede ser objeto de aseguramiento, debiendo excluirse expresamente de las garantías asegurables contenidas en el artículo 12 LAT. Considera la asociación de aseguradoras que teniendo la indemnización adicional "carácter penal, no puede ser objeto de seguro, por ser inmoral todo contrato que tiende a librar de una pena".

Frente a la petición de prohibir el aseguramiento de la indemnización adicional promovida por la asociación de compañías de seguros, la postura de la sección primera técnico-administrativa del Instituto de Reformas Sociales es clara. Partiendo de que el seguro de accidentes contemplado en el artículo 12 LAT resulta voluntario, "ninguna Compañía está obligada a contratar seguros que comprendan el caso de la citada disposición 5 . Mas, aunque la Ley no contuviera autorización alguna para que el patrono pudiera asegurar a sus obreros contra los accidentes, aquél podría hacerlo libremente en su propio interés, y es natural que la Compañía aseguradora procurase al realizar cualquier contrato, enterarse de las condiciones de seguridad en que los

57 En dicha comisión estaban representadas las siguientes compañías: "Caja de Previsión y Socorro, La Hispania, de Barcelona; La Vasco-Navarra, de Pamplona; La Preservatrice, La Foncière, de París, y la Asicuratrice

Italiana, de Milán, y la Anonnima de Accidentes, Italiana”. Instituto de Reformas Sociales, Proyecto de reforma de la Ley de Accidentes del Trabajo de 30 de enero de 1900, Imprenta de la Sucesora de M. Minuesa de los Ríos, Madrid, 1908, p. 120.

58 Instituto de Reformas Sociales, Preparación de la reforma de Ley de Accidentes del Trabajo de 30 de enero de 1900, Informe de la sección primera técnico-administrativa, Imprenta de la Sucesora de M. Minuesa de los Ríos, Madrid, 1905, p. 117.

59 Instituto de Reformas Sociales, Proyecto de reforma de la Ley de Accidentes del Trabajo de 30 de enero de 1900, cit., p. 149. 
obreros trabajan; el hecho de que la Ley permita el seguro con relación a la disposición $5^{a}$, en nada afecta a las relaciones jurídicas que libremente puedan contraer las Compañias y los patronos" ${ }^{20}$.

Prescindiendo de la respuesta proporcionada a la asociación de compañías aseguradoras, el aseguramiento de la indemnización adicional no fue objeto de controversia alguna, ni por la parte obrera, ni por las secciones primera y segunda técnico-administrativas del Instituto de Reformas Sociales, ni por la denominada sección jurídica. Se admitía con naturalidad el aseguramiento de esta indemnización, que podía ser libremente suscrita por el patrono si así lo deseara.

El proyecto de reforma, tras los trabajos previos realizados por las distintas secciones del Instituto de Reformas Sociales, pasó a ser discutido en el pleno de este organismo el 9 de noviembre de 1905. El texto articulado, como se ha señalado, no tenía ninguna referencia a la prohibición de aseguramiento de la indemnización adicional. A lo largo de los meses que duró el debate en el pleno del Instituto de Reformas Sociales se introdujeron distintas enmiendas que fueron objeto de distintos posicionamientos y de acalorados debates. Entre todas estas enmiendas, en la sesión del 1 de marzo de 1906 se introduce la prohibición de aseguramiento de la indemnización adicional a solicitud de José Maluquer y Salvador ${ }^{61}$, vocal del Instituto de Reformas Sociales a propuesta del Gobierno y con gran experiencia en el ámbito de los seguros al haber desempeñado labores como asesor general de seguros del Ministerio de la Gobernación y funciones directivas en la compañía de seguros La Equitativa ${ }^{62}$.

Por parte del Sr. Maluquer se propone la adición al artículo $6.5^{\circ}$ de un párrafo, que coincide sustancialmente con lo propuesto en fase de tramitación por la Comisión permanente de las compañías de seguros: "El riesgo de la indemnización especial a que se refiere esta disposición $5^{\circ}$ no puede ser materia de seguro. Si se probase que alguna entidad aseguradora lo asumía, deberá ser apercibida, y caso de persistir en pactar dicha condición, procederá que se le prive de la autorización oficial que tuviere reconocida a los efectos de la presente Ley". La propuesta del Sr. Maluquer es aprobada sin discusión en el pleno del Instituto de Reformas Sociales ${ }^{63}$. Se cambiaba de este

60 Instituto de Reformas Sociales, Preparación de la reforma de Ley de Accidentes del Trabajo de 30 de enero de 1900, Informe de la sección primera técnico-administrativa, cit., p. 126.

61 Boletín del Instituto de Reformas Sociales, nº 22 (1906), p. 762.

62 Para conocer detalladamente la trayectoria de José Maluquer y Salvador, cfr. PULIDo FERNÁNDEZ, A., Biografía del Excelentísimo Señor José Maluquer y Salvador, Sobrinos de la Sucesora de M. Minuesa de los Ríos, Madrid, 1924, y Monereo PÉREZ, J.L., “José Maluquer y Salvador”, Revista de Derecho de la Seguridad Social, no 1 (2014), pp. 335-355.

63 Instituto de Reformas Sociales, Proyecto de reforma de la Ley de Accidentes del Trabajo de 30 de 
modo el posicionamiento mantenido por la estructura técnico-administrativa de este organismo en los trabajos previos en relación con el aseguramiento de la indemnización adicional sin aportar ninguna justificación que fundara esta variación. Resulta cuanto menos sorprendente que no existiera en el pleno ningún tipo de debate sobre la enmienda introducida por el Sr. Malquer, que suponía un giro radical al criterio mantenido por la sección primera del Instituto de Reformas Sociales; y ello, teniendo en cuenta que la práctica totalidad de las enmiendas eran objeto de controversia en el pleno. En este sentido, muchas de las enmiendas en materia de seguro de accidentes fueron introducidas por el Sr. Maluquer, siendo todas ellas objeto de discusión salvo la que se refiere al artículo 6. 5 $5^{\circ}$. También parece curioso que el presidente de la sección primera técnico-administrativa, Adolfo Posada, que había manifestado su posición a favor del aseguramiento en el informe de 10 de abril de 1905, no realizará ningún tipo de observación en el pleno, como sí que realizó en relación con otros asuntos que suponían variar los trabajos previos de la sección que presidía.

Pese a que existe numerosa documentación que recoge de forma detallada todo el proceso de elaboración de la reforma, de la misma no se deducen cuáles fueron las razones reales que llevaron al Instituto de Reformas Sociales de rechazar frontalmente la petición de las compañías de seguros a acogerla sin ningún tipo de reticencia. Parece en cierto modo contradictorio que se prohibiera el aseguramiento de la indemnización adicional cuando uno de los principales objetos de la reforma era garantizar la percepción de las indemnizaciones por parte de los trabajadores accidentados frente a la posible insolvencia o incumplimiento empresarial, desarrollando las instituciones vinculadas al seguro de accidentes.

Todo apunta a que las razones teóricas que se adujeron para prohibir el aseguramiento vinieron ligadas a la función preventiva del recargo ${ }^{64}$. Así se deduce de la respuesta de la sección primera técnico-administrativa a varias sociedades obreras de Barcelona que reclamaban la aplicación de la indemnización del artículo 5.5 LAT. En dicha respuesta, con gran dosis de escepticismo, se señala que la prohibición del aseguramiento tiene como finalidad fomentar la aplicación del artículo 5.5\%, pero que "si con esta declaración legal no basta para evitar la inaplicación del precepto, no cree la Sección que es de su competencia proponer los remedios reglamentarios" ${ }^{25}$. El informe, firmado

enero de 1900, cit., p.229

64 Parte de la doctrina de la época había considerado que la finalidad del artículo $5.5^{\circ}$ LAT consistía en que el patrono utilizara los mecanismos de previsión necesarios, finalidad que sería burlada si se entendiera el recargo incluido en el seguro, ya que entonces el empresario perdería interés por cumplir su obligación preventiva. OYUELOS, R., Jurisprudencia de Accidentes de Trabajo y Tribunales Industriales, Sobrinos de la Sucesora de M. Minuesa de los Ríos, Madrid, 1917, p. 115.

65 Informe de 16 de febrero de 1907 sobre la exposición del Sr. Pinart Novellas (en nombre de varias 
por Adolfo Posada, traslucía el descontento de la sección primera técnico-administrativa con la solución que el pleno del Instituto de Reformas Sociales adoptó de prohibir el aseguramiento de la indemnización adicional.

Más allá de argumentos teóricos, resulta difícil poder verificar cuáles fueron los auténticos motivos que, en un plano operativo, facilitaron la adición de la prohibición de aseguramiento en el pleno del Instituto de Reformas Sociales. Posiblemente ello se debiera a un cúmulo de circunstancias, entre las cuales, el perfil de José Maluquer y Salvador y la presión de la asociación de las compañías de seguros, que habían obtenido unos malos resultados en los primeros años de gestión del seguro de accidentes ${ }^{66}$, se nos presentan como necesariamente concurrentes. Apoyan esta tesis las ilustrativas palabras del diputado Rafael Guerra del Río en fase de tramitación parlamentaria de la reforma de la Ley de Accidentes del Trabajo, al señalar: "Hay otras influencias que yo he llamado de origen no tan puro, y que son influencias directas de las Compañias mercantiles de seguros. Aunque me lo supongo, y desde luego aseguro que no ha sido en la Comisión ni en el Congreso de los Diputados, no sé en qué momento, ha habido aqui la influencia de un colaborador al dictado, consciente o inconsciente, de las Compañias mercantiles de seguros. A través del engranaje de la ley, se nota su paso en distintas ocasiones" ${ }^{67}$.

Con independencia de lo expuesto, lo cierto es que, introducida la prohibición de aseguramiento en el artículo $6.5^{\circ}$ del proyecto de reforma de la LAT de 1907, el mismo precepto y con la misma redacción será reproducido en los proyectos siguientes de $1910^{68}, 1914^{69}, 1916^{70}$ y $1919^{71}$.

Finalmente, la prohibición de aseguramiento quedará por primera recogida normativamente en el artículo $6.5^{\circ}$ de la Ley de Accidentes del Trabajo de 10 de enero de 1922, que acogiendo literalmente el texto de los distintos proyectos de reforma, disponía: "El riesgo de indemnización especial a que se refiere esta disposición $5^{\mathrm{a}}$ no podrá ser materia de seguro. Si se probare que alguna entidad aseguradora lo asumía, deberá ser apercibida, $\mathrm{y}$, caso de persistir en dicha condición, se le retirará la

sociedades obreras de Barcelona) pidiendo ciertas reformas de la Ley de Accidentes. Instituto de Reformas Sociales, Proyecto de reforma de la Ley de Accidentes del Trabajo de 30 de enero de 1900, cit., p.343

${ }^{66}$ Vid. Revista Ilustrada de Banca, Ferrocarriles, Industria y Seguros, 10 de febrero de 1904, p. 79.

${ }^{67}$ Diario de las Sesiones de Cortes, 16 de diciembre de 1921, nº 108, p. 4885.

${ }^{68}$ Diario de las Sesiones de Cortes, 18 de julio de 1910, $\mathrm{n}^{\circ} 28$ (apéndice $4^{\circ}$ ).

69 Diario de las Sesiones de Cortes, 9 de junio de 1914, $\mathrm{n}^{\circ} 47$ (apéndice $4^{\circ}$ ).

70 Diario de las Sesiones de Cortes, 5 de junio de 1916, $\mathrm{n}^{\circ} 20$ (apéndice $3^{\circ}$ ).

${ }^{71}$ Diario de las Sesiones de Cortes, 18 de noviembre de 1919, ${ }^{\circ} 34$ (apéndice $3^{\circ}$ ). 
autorización oficial que se le hubiere concedido a los efectos de la presente Ley". Desde entonces y hasta la actualidad la prohibición de aseguramiento del recargo de prestaciones ha sido una constante en nuestro ordenamiento jurídico, y fuente de numerosos conflictos interpretativos ${ }^{72}$.

\section{Breve reflexión final}

Conocer la historia del recargo de prestaciones es conocer la historia del derecho del trabajo en España. Esta institución ha logrado permanecer en nuestro ordenamiento jurídico con perseverancia y obstinación desde los inicios de nuestra legislación obrera hasta la actualidad. El recargo, ligado en sus inicios a la prevención de los accidentes, pero con claro sentido indemnizatorio, ha ido evolucionando en su alcance y contenido a la par que la legislación obrera se iba desarrollando y conformando un auténtico derecho del trabajo.

Desde sus orígenes, el recargo de prestaciones ha sido protagonista de numerosos conflictos interpretativos y objeto de complejos constructos teóricos que han ido modificando la esencia de la institución con el fin de ajustarla al contexto en el que hubiera de ser aplicada. El largo recorrido histórico del recargo de prestaciones lo ha ido debilitando en sus fundamentos. Su capacidad de acomodación no ha alcanzado a poder cohonestarse con el desarrollo que la legislación laboral, especialmente la preventiva, ha experimentado en estas tres últimas décadas. Esta falta de adaptación ha intentado ser salvada mediante construcciones doctrinales y jurisprudenciales que, lejos de revitalizar la institución, han acentuado las incertezas que tradicionalmente la han acompañado.

Tras más de un siglo de interminables y agotadores debates, parece necesario que el recargo de prestaciones se reformule y supere definitivamente los clásicos problemas ligados a su naturaleza jurídica, integrándose satisfactoriamente en el complejo sistema de responsabilidades e indemnizaciones que configura nuestro ordenamiento jurídico en relación con los accidentes de trabajo. Esta labor de cuestionamiento ha de ser honda y sosegada, pero abierta y sin prejuicios, valorando, entre otros extremos, las funciones que desempeña el recargo en la actualidad, si en el cumplimiento de dichas funciones se solapa con otras instituciones con finalidades similares, si en atención a su finalidad y naturaleza actual debe ser objeto de aseguramiento, o si el recargo es el mecanismo

\footnotetext{
72 Ilustrativa de este conflicto resulta la STS, 23 de marzo de 2015 ( $\mathrm{n}^{\circ}$ rec. 2057/2014), que alcanza a cuestionar la propia prohibición de aseguramiento del recargo. Cfr. especialmente el voto particular del Magistrado Excmo. Sr. D. José Manuel López García de la Serrana, y al que se adhiere el Excmo. Sr. D. José Luis Gilolmo López. Acoge el voto particular la excelente construcción teórica desarrollada por Desdentado Bonete, A., "El recargo de prestaciones de Seguridad Social y su aseguramiento. Contribución a un debate", Revista de Derecho Social, nº 21 (2003), pp. 19-22.
} 
idóneo de persuasión y concienciación preventiva de los empresarios contemporáneos. En esta tarea analítica y reflexiva, la historia normativa y de las instituciones se nos presenta como una herramienta indispensable para entender el sentido del recargo de prestaciones, ligado esencialmente al ámbito preventivo. El pasado ha de ayudarnos a entender el presente, y también a programar el futuro; futuro en el que aún desconocemos si terminará teniendo cabida un eventual recargo de prestaciones del s. XXI con existencia autónoma, o, si finalmente, el mismo acabará por diluirse siendo absorbido por el complejo sistema sancionador, reparador e indemnizatorio que conforma nuestro actual marco jurídico preventivo. 